\title{
Contractile activity of the human colon: lessons from 24 hour studies
}

\author{
G Bassotti, M D Crowell, W E Whitehead
}

\begin{abstract}
The motor function of the colon is probably the least understood of the various hollow viscera of the human body. ${ }^{1-4}$ This is partly because of the marked variability of colonic motor function ${ }^{5-8}$ and the short recording periods usually used, generally not exceeding three hours. ${ }^{-13}$ Most of the data available on human colonic motility originate from investigations conducted in the most distal portions of the viscus, ${ }^{39-13}$ because of technical difficulties in reaching its proximal portions. Although attempts have been made to solve these problems through the ingestion of radiotelemetric pressure sensors, ${ }^{14-18}$ these efforts have been hampered by intermittent signal loss and the inability to control the location of the capsule within the gastrointestinal tract. To overcome these problems, techniques have recently been developed that permit prolonged recordings (24 hours or more) of myoelectrical' and contractile activity of the human colon, with both perfused $^{1920}$ and solid-state manometric systems. ${ }^{21-24}$ The present paper reviews the current experience in $\mathbf{2 4}$ hour recording from the human colon, with a primary emphasis on the more forceful propulsive contractile activity associated with the so called mass movements.
\end{abstract}

(Gut 1993; 34: 129-133)

Center for the Study of Functional and Motility Disorders of the Gut, Departments of

Departments of
Psychiatry and Medicine The Johns Hopkins University School of

Medicine and Francis

Scott Key Medical

Center, Baltimore, $M d$,

USA

G Bassotti

$M$ D Crowell

W E Whitehead

Laboratorio di Motilitá Intestinale, Istituto di Gastroenterologia ed

Endoscopia Digestiva, Universitá di Perugia,

Perugia, Italy

G Bassotti

Correspondence to: Dr Gabrio Bassotti, Laboratorio di Motilit Intestinale, Istituto di Gastroenterologia ed Endoscopia Digestiva Policlinico Monteluce, 06100 Perugia, Italy.

Accepted for publication 21 May 1992
Diurnal patterns of motility

It has been suggested on the basis of short che regular pattern has been observed the colon more than $25 \mathrm{~cm}$ from the anal verge. ${ }^{819}$ periods of observation that sleep depresses colonic motility, ${ }^{29}$ but this was not confirmed by some authors, ${ }^{30}$ and others noted a wide variability of rectosigmoid motor activity during sleep. ${ }^{6}$ Prolonged studies have consistently shown decreased motor activity during the night and during daytime naps, ${ }^{192} 22$ however, providing a more definitive answer to the contradictory data previously available on colonic motility during sleep. ${ }^{29-32}$

Morning awakening provides a strong stimulus for increased colonic contractile activity. ${ }^{19}$ Moreover, increased motility was observed immediately after occasional afternoon naps. ${ }^{19}$ This observation has also been supported by a recent report on healthy volunteers, showing that sudden awakening is accompanied by a strong increase in segmental motility from the colon. ${ }^{33}$

Contractile activity increases promptly with food ingestion (within one to three minutes after the first mouthful of food) and lasts several hours after ingestion of a meal. ${ }^{3+}$ The early component of the meal stimulated increase in contractile activity is thought to be neurally mediated and the late component is thought to be hormonally mediated. ${ }^{+}$The physiological basis of this response, however, is not well understood. The colonic motor response to eating, characterised by both low amplitude, frequent, irregularly spaced contractions, and occasional highamplitude propagated contractions, show that eating is one of the most physiological and powerful stimuli to elicit colonic motility. ${ }^{3+39}$ One investigation aimed at characterisation of this response showed that it differs in the various colonic segments, with the proximal ones displaying brisk and less sustained contractile activity than the distal ones. ${ }^{38}$ On the basis of this and other studies, ${ }^{+0+1}$ it has been suggested that a functional physiological specialisation does exist in the human colon, with the proximal segments representing sites of mixing and storage of contents, whereas the distal ones would act as a conduit to propel faeces to the rectal ampulla. ${ }^{38+0}$

The above observations are further supported by evaluation of defecatory patterns. Most individuals experience the urge to defecate on morning awakening and after meals, when colonic motility is known to peak.

High amplitude propagated contractions and their relationship to mass movements

Mass movements were first described by Hertz 
in $1907^{+2}$ (who also noted their relationship to meals) ${ }^{+3}$ and later by Holzknecht in 1909 , who is frequently credited with their discovery. ${ }^{H}$ As described by radiological methods, mass movements define an infrequent, aborally propagated displacement of colonic contents for long distances along the viscus. ${ }^{1317+5+6}$ Only a few manometric studies have attempted to characterise the motility patterns associated with mass movements. These investigations were performed under non-physiological conditions that is, through colostomies, ${ }^{47-49}$ or after colonic stimulation with laxatives or balloon distension. ${ }^{5051}$

Recent studies which used long term recording of colonic motility with a colonoscopically positioned manometric probe, ${ }^{19-212+}$ and simultaneous measurement of transit through intraluminally instilled radiolabelled compounds ${ }^{26}$ have provided more detailed information on the relationship of motility to mass movements: (1) high amplitude propagated contractions (pressure waves greater than $50 \mathrm{mmHg}$ which are propagated more than $10 \mathrm{~cm}$ ) occur infrequently in normal subjects, averaging six per 24 hours. (2) Because their amplitude, which may exceed $200 \mathrm{mmHg}$, high amplitude propagated contractions are easily differentiated from other colonic contractions. Some studies, however, suggest that low amplitude waves (typically $10-30 \mathrm{mmHg}$ ) may also propagate over relatively long distances and may move colonic contents. ${ }^{2852}$ These low amplitude propagated contractions are reported to be more frequent. It is unknown whether low amplitude propagated contractions and high amplitude propagated contractions have the same physiological basis and serve the same function - that is, whether they are parts of a continuum of propagated contractions. (3) High amplitude propagated contractions start from the ascending colon ${ }^{20}$ (old observations also suggest that the appendix may be involved in such forceful activity), ${ }^{53}$ and most are propagated in an aboral direction. Rarely, they may propagate in an oral direction..$^{24}$ (4) High amplitude propagated contractions are frequently associated with a crampy urge to defecate or actual defecation and sometimes with borborygmi. ${ }^{19} 20$ Despite their high amplitude, however, they are rarely associated with pain. (5) High amplitude propagated contractions are associated with specific physiological or behavioural events, being more frequent during the day ( $80 \%$ of occurrences), after meals $(50 \%$ of occurrences), and upon awakening in the morning (33\% of occurrences). ${ }^{2024}$

The function of these forceful propulsive waves seems chiefly that of shifting a relatively large quantity of intraluminal content aborally for long distances within the colonic lumen, thereby determining a right-to-left gradient important for the initiation of defecation. ${ }^{+}$Not all high amplitude propagated contractions result in an immediate defecation, however, and not all defecations are immediately preceded by high amplitude propagated contractions, because subjects normally store stool in the rectum or distal bowel until defecation is socially convenient. High amplitude propagated contractions are elicited by some types of laxatives (especially bysacodyl), ${ }^{46+75054}$ which provides further evidence of their role in defecation.

To date, no data are available about the neurohumoral mechanisms underlying high amplitude propagated contraction onset. One recent paper showed that cholinergic stimulation does not evoke this kind of propagated activity, although it does increase segmental contractions. ${ }^{55}$ Hardcastle and $\mathrm{Mann}^{+8}$ showed that propagation depends on the integrity of the enteric nervous system, but the role of the extrinsic nerves has not been assessed.

\section{Pathophysiological applications of prolonged colonic recordings}

Apart from increasing our understanding of normal colonic motility patterns, prolonged recordings are providing useful information about different pathological conditions. A recent study showed that chronically constipated subjects displayed significantly fewer high amplitude propagated contractions and a decreased frequency of urge to defecate, ${ }^{56}$ suggesting that one important pathophysiological mechanism for constipation may be a decrease in the propulsive ability of the viscus. Other studies have disclosed that patients complaining of slow transit constipation have impaired cyclic rectal activity, ${ }^{575}$ suggesting that these patients have a motor neuropathy.

Although irritable bowel syndrome is commonly believed to be a colonic motility disorder, the evidence supporting this hypothesis is inconsistent. Most of the motility studies on irritable bowel syndrome patients have been conducted for brief periods of time in the very distal portions of the viscus. ${ }^{596}$ Prolonged recordings have recently confirmed that constipation predominant irritable bowel syndrome patients have significantly fewer high amplitude propagated contractions than controls, implying that they have impaired colonic propulsive activity. ${ }^{61}$ Diarrhoea predominant irritable bowel syndrome patients were found to have normal numbers of high amplitude propagated contractions, although the amplitude of high amplitude propagated contractions was significantly reduced relative to controls. ${ }^{62}$ The physiological significance of the findings in diarrhoea predominant irritable bowel syndrome patients, which were contrary to expectation, is unknown.

Technical limitations and critical evaluation of colonic manometric recordings

Although open tipped tubes and intraluminal strain gauges have been widely used for the measurement of contractile activity in the colon, it has been argued on theoretical grounds that they detect only lumen occluding contractions, and therefore underestimate the incidence of contractile activity. ${ }^{63}$ A 4 direct comparison of serosal strain gauges to open tipped catheters, however, ${ }^{65}$ showed that open tipped tubes detected $87 \%$ of all tonic contractions and $80 \%$ of all phasic contractions recorded by serosal strain gauges. The contractions recorded were of varying amplitudes, and Cook et al's tracings show good reproduction by the open tipped tube 
recordings of both the shape and amplitude of contractions measured from the serosal strain gauges throughout a wide range of amplitudes. Thus, open tipped tubes and intraluminal solid state pressure transducers appear to provide a good estimate of the amount and characteristics of contractile activity.

Another concern which has been raised about the validity of intraluminal recordings is that the bowel evacuation which is used to facilitate placing the probe may alter contractile patterns. Dinoso et al have show that contractile activity is greater after a cleansing enema than in the unprepared colon. ${ }^{6}$ Differences in motility, however, can be recorded after bowel preparation which are consistent with the typical symptoms of the patients studied. ${ }^{5661}$ Moreover, as the intraluminal contents may influence motility, it is safer to infer that differences between individuals in motility patterns are causally related to their altered bowel habits if these motility patterns are seen when the intraluminal contents are similar - that is, after bowel evacuation, as opposed to varying from liquid to hard masses.

\section{Comparative physiology}

The lack of an appropriate animal model has hampered progress on the investigation of colonic motor activity. The structure and function of the large intestine varies greatly among mammals, ${ }^{67}$ with variability concerning mostly the extent of the sacculation and the size of the caecum. ${ }^{6768}$ The simplest large intestines, exhibiting a vestigial caecum and no sacculations, are found in the rat, cat, and dog, which are the animals most frequently used in studies on colonic motor function. The colon in these animals is a smooth, uniform tube, without sacculations or teniae, and it is approximately Cshaped and devoid of the sharp angulations seen in man. ${ }^{68}$ Furthermore, the electrophysiological properties of the colonic circular muscle of the cat and dog are very different from that of the human colon. ${ }^{69-71}$ In recent years, however, the canine colon has become a standard model for colonic motility studies and, although it displays some kinds of contractile activity not seen in man, ${ }^{7273}$ it has been useful for investigating neuropharmacological interactions.

The best animal model for colonic physiology in man appears to be the pig. This animal has a similar diet, the colon has a caecum similar to man, and the anatomy is similar at the microscopic level. Like man, the pig shows spontaneous constipation and diarrhoea (perhaps pigs also have irritable bowel syndrome...). These two species also have similar patterns of contractile activity. ${ }^{74}$ The pig has rarely been used in physiology laboratories because of its size and temperament, but the development by animal breeders of a minipig with better temperament may change this.

\section{Future directions}

Prolonged pancolonic recordings may play an important role in elucidating the physiological mechanisms underlying different patterns of colonic motility and their functional signific- ance. For example, simultaneous monitoring of the EEG and large bowel motility has shown that sleep has profound inhibitory effects on overall colonic contractions and is the major determinant of the daily variations of motility. ${ }^{75}$ Abnormalities in the inhibition of motility during sleep should be evaluated in patients who report nocturnal faecal incontinence.

Solid state catheters, which produce data closely comparable with those acquired from perfused tubes, ${ }^{212+76}$ will permit more physiological recordings from freely ambulating subjects in their normal work and social environment, once some technical limitations are resolved - that is, fixed position of recording points, difficulty in spacing sensors less than $5 \mathrm{~cm}$ from each other, fragility of the probes, few recording points available, expensive price, and maintainance. Moreover, the application of the barostat to long term recordings of colonic motility, ${ }^{77} 78$ may prove useful to assess other pathopysiological aspects of functional colonic disorders.

Finally, preliminary results from the evaluation of severely constipated patients for whom surgery is being considered suggest a possible diagnostic role for prolonged colonic recordings, especially when coupled with pharmacologic stimulation. ${ }^{79}$ This fact is particularly significant in light of the poor outcomes sometimes reported after surgical procedures for constipation ${ }^{80-84}$; a thorough in depth functional evaluation, especially coupled to small bowel recordings, in order to exclude a more generalised gastrointestinal motor disorder, ${ }^{795}$ might yield more effective results after surgery in patients with chronic constipation.

1 Misiewicz JJ. Colonic motility. Gut 1975; 16: 311-4.

2 Huizinga JD, Daniel EE. Control of human colonic function. Dig Dis Sci 1986; 31: 865-77.

3 Christensen J. Motility of the colon. In: Johnson LR, ed. Physiology of the gastrointestinal tract. 2nd ed. New York: Raven Press, 1987: 595-629.

4 Sarna SK. Physiology and pathophysiology of colonic motor activity. Part I. Dig Dis Sci 1991; 36: 827-62.

5 Wyman JV, Heaton KW, Wicks ACB. Variability of colonic function in healthy subjects. Gut 1978; 19: 146-50.

6 Kerlin P, Zinsmeister A, Phillips S. Motor responses to food of the ileum, proximal colon, and distal colon of healthy humans. Gastroenterology 1983; 84: 762-70.

7 Frexinos J, Bueno L, Fioramonti J. Diurnal changes in myoelectric spiking activity of the human colon. Gastroenterology 1985; 88: 1104-10.

8 Bassotti G, Bucaneve G, Pelli MA, Morelli A. Contractile frequency patterns of the human colon. $\mathcal{F}$ Gastrointest Motility 1990; 2: 73-8.

9 Chaudary NA, Truelove SC. Human colonic motility. A comparative study of normal subjects, patients with ulcerative colitis and patients with irritable colon syndrome. I. Resting patterns of motility. Gastroenterology 1961; 40: $1-46$.

10 Ritchie JA, Ardran GM, Truelove SC. Motor activity of sigmoid colon in humans. A combined study of intraluminal pressure recording and cineradiography. Gastroenterolog. 1962; 43: 642-68.

11 Snape WJ, Matarazzo SA, Cohen S. Effect of eating and gastrointestinal hormones on human colonic myoelectric and motor activity. Gastroenterolog' 1978; 75: 373-8.

12 Dinoso VP, Murthy SNS, Goldstein J, Rosner B. Basal motor activity of the distal colon: a reapparaisal. Gastroenterology 1983; 85: 637-42.

13 Narducci F, Bassotti G, Daniotti S, Del Soldato P, Pelli MA. Morelli A. Identification of muscarinic receptor subtype mediating colonic response to eating. Dig Dis $S c i$ 1985; $\mathbf{3 0}$ : $124-8$.

14 Ramorino ML, Colagrande C. Intestinal motility. Preliminary studies with telemetering capsules and synchronised fluorocinematography. Am 7 Dig Dis 1964; 9: 6+-71. 
15 Misiewicz JJ, Connell AM, Pontes A. Comparison of the effect of meals and prostigmin on the proximal and distal colon in patients with and without diarrhoea. Gut 1966; 7: 468-73.

16 Misiewicz JJ. Measurement of intraluminal pressures. Radiotelemetry, design of manometric studies and computer analysis of results. Am $\mathcal{F}$ Dig Dis 1968; 13: 389-96.

17 Holdstock DJ, Misiewicz JJ, Smith T, Rowlands EN Propulsion (mass movements) in the human colon and its relationship to meals and somatic activity. Gut 1970; 11: 91-9.

18 Browning CR, Valori RM, Wingate DL. Receiving, decoding and noise-limiting systems for a new pressure-sensitive ingestible radio-telemetric capsule. $\mathcal{F}$ Biomed Eng 1983; 5: ingestible.

19 Narducci F, Bassotti G, Gaburri M, Morelli A. Twenty four hour manometric recording of colonic motor activity in healthy man. Gut $1987 ; 28: 17-25$.

20 Bassotti G, Gaburri M. Manometric investigation of highamplitude propagated contractile activity of the human colon. Am f Physiol 1988; 255: G660-4.

21 Crowell MD, Whitehead WE, Cheskin L, Kamal N, Schuster MM. Circadian and diurnal aspects of high amplitude propagated contractile activity from the colon in asymptomatic people. 7 Gastrointest Motility 1989; $1: 75$.

22 Kumar D, Williams NS, Waldron D, Wingate DL. Prolonged manometric recording of anorectal motor activity in ambulant human subjects: evidence of periodic activity. $G u t$ 1989; 30: 1007-11.

23 Soffer EE, Scalabrini P, Wingate DL. Prolonged ambulant monitoring of human colonic motility. Am f Physiol 1989; 257: G601-6.

24 Crowell MD, Bassotti G, Cheskin LJ, Schuster MM, Whitehead WE. Method for prolonged ambulatory monitoring of high-amplitude propagated contractions from colon. Am F Physiol 1991; 261: G263-8.

25 Ritchie JA. Movements of segmental constrictions in the human colon. Gut 1971; 12: 350-5.

26 Moreno-Osset E, Bazzocchi G, Lo S, Trombley H, Ristow E, Reddy SN, et al. Association between postprandial changes in colonic intraluminal pressure and transit. Gastroenterology 1989; 96: 1265-73.

27 Orkin BA, Hanson RB, Kelly KA. The rectal motor complex. f Gastrointest Motility 1989; 1: 5-8.

28 Orkin BA, Hanson RB, Kelly KA, Phillips SF, Dent J. Human anal motility while fasting, after feeding, and during sleep. Gastroenterology 1991; 100: 1016-23.

29 Hagihara PF, Griffen PO. Physiology of the colon and rectum. Surg Clin North Am 1972; 52: 797-805.

30 Posey EL, Bargen JA. Observations of normal and abnormal human intestinal motor function. Am $\mathcal{F}$ Med Sci 1951; 221: $10-20$

31 Adler HF, Atkinson AJ, Ivy AC. A study of the motility of the human colon. An explanation of dysynergia of the colon, or of the 'unstable colon'. Am F Dig Dis 1941; 8: 197-202.

32 Rosemblum MJ, Cummings AJ. The effect of sleep and of amytal on the motor activity of the human sigmoid colon. Gastroenterology 1954; 27: 445-50.

33 Bassotti G, Bucaneve G, Betti C, Morelli A. Sudden awakening from sleep: effects on proximal and distal colonic contractile activity in man. Eur $\mathcal{F}$ Gastroenterol Hepatol 1990; 2: $475-8$.

34 Duthie HL. Colonic response to eating. Gastroenterologv 1978; 75: 527-9.

35 Snape WJ, Wright SJ, Battle WM, Cohen S. The gastrocolic response: evidence for a neural mechanism. Gastroenterology 1979; 77: 1235-40.

36 Christensen J. The response of the colon to eating. Am $\mathcal{F}$ Clin Nutr 1985; 42: 1025-32.

37 Frexinos J, Fioramonti J, Bueno L. Response colique a l'alimentation. Regulation et anomalies. Gastroenterol Clin Biol 1986; 10: 837-40.

38 Bassotti G, Betti C, Imbimbo BP, Pelli MA, Morelli A. Colonic motor response to eating: a manometric investigation in proximal and distal portions of the viscus in man. Am $\mathcal{F}$ Gastroenterology 1989; 84: 118-22.

39 Bassotti G. The response of the human colon to food ingestion. Diabetes Nutr Metab 1990; 3: 91-4.

40 Krevsky B, Malmud LS, D'Ercole F, Maurer AH, Fisher RS. Colonic transit scintigraphy, a physiologic approach to the quantitative measurement of colonic transit in humans. Gastroenterology 1986; 91: 1102-12.

41 Bassotti G, Imbimbo BP, Gaburri M, Daniotti S, Morelli A. Transverse and sigmoid colon motility in healthy humans: effects of eating and of cimetropuim bromide. Digestion 1987; 3: 163-9.

42 Hertz AF. The passage of food along the human alimentary canal. Guy's Hosp Rep 1907; 61: 389-427.

43 Hertz AF, Newton A. The normal movements of colon in man. F Physiol (London) 1913; 47: 57-65.

44 Holzknecht G. Die normale Peristaltik des Colon. Munch Med Wochenschr 1909; 56: 2401-3.

45 Ritchie JA. Colonic motor activity and bowel function. I. Normal movement of contents. Gut 1968; 9: +42-56.
66 Ritchie JA. Mass peristalsis of the human colon after contact with oxyphenisatin. Gut 1972; 13: 211-9.

47 Hardcastle JD, Mann CV. Study of large bowel peristalsis. Gut 1968; 9: 512-20.

48 Hardcastle JD, Mann CV. Physical factors in the stimulation of colonic peristalsis. Gut $1970 ; 11: 41-6$.

49 Garcia D, Hita G, Mompean B, Hernandez A, Pellicer E, Morales G, et al. Colonic motility: electric and manometric description of mass movement. Dis Colon Rectum 1991; 34: 577-84.

50 Torsoli A, Ramorino ML, Ammaturo MV, Capurso L, Paouluzi P, Anzini F. Mass movements and intracolonic pressures. Am F Dig Dis 1971; 16: 693-6.

51 Narducci F, Bassotti G, Gaburri M, Solinas A, Fiorucci S, Morelli A. Distention stimulated motor activity of the human transverse, descending and sigmoid colon. Gastroenterology 1985; 88: 1515 .

52 Furukawa Y, Cook IJ, Panagopoulos V, Simula M, McEvoy $\mathrm{D}$, Sweeney J, et al. Regional and diurnal variation in human colonic pressure activity characterised by prolonged pancolonic manometry. Gastroenterology 1990; 98: A352.

53 Macewen $W$. The function of the caecum and appendix. Lancet 1904; 8: 995-1000.

54 Torsoli A, Ramorino ML, Crucioli V. The relationships between anatomy and motor activity of the colon. Am $\mathcal{F}$ Dig Dis 1968; 13: 462-7.

55 Bassotti G, Imbimbo BP, Betti C, Erbella GS, Pelli MA, Morelli A. Edrophonium chloride for testing colonic contractile activity in man. Acta Phvsiol Scand 1991; 141: 28993.

56 Bassotti G, Gaburri M, Imbimbo BP, Rossi L, Farroni F, Pelli $\mathrm{MA}$, et al. Colonic mass movements in idiopathic chronic constipation. Gut 1988; 29: 1173-9.

57 Waldron DJ, Kumar D, Hallan RI, Wingate DL, Williams NS. Evidence for motor neuropathy and reduced filling of the rectum in chronic intractable constipation. Gut 1990; 31: $1284-8$.

58 Bassotti G, Betti C, Pelli MA, Morelli A. Prolonged ( 24 hour manometric recording of rectal contractile activity in patients with slow transit constipation. Digestion 1991; 49: $72-7$

59 Snape WJ. Irritable colon syndrome. In: Snape WJ, ed. Pathogenesis of functional bowel disease. New York: Plenum Publishing, 1989: 227-47.

60 Lind CD. Motility disorders in the irritable bowel syndrome. Gastroenterol Clin North Am 1991; 20: 279-95.

61 Crowell MD, Whitehead WE, Cheskin LJ, Schuster MM. Twenty-four hour ambulatory monitoring of peristaltic activity from the colon in normal and constipationpredominant IBS patients. Gastroenterologv 1989; 96: A103.

62 Bassotti G, Betti C, Erbella GS, Crowell MD, Whitehead W'E, Pelli MA, et al. Colonic mass movements in diarrheapredominant IBS patients. Gastroenterologv 1990; 98: A326.

63 Wingate DL. Methodology of motility. In: Christensen J, Wingate DL, eds. A guide to gastrointestinal motility. Bristol: John Wiley, 1983: 215-29.

64 Karaus M, Wienbeck M. Colon. In: Kumar D, Gustavsson S, eds. An illustrated guide to gastrointestinal motility. Chichester: John Wiley, 1988: 207-28.

65 Cook IJ, Reddy SN, Collins SM, Daniel EE. The influence of recording techniques on measurement of canine colonic motility. Dig Dis Sci 1988; 33: 998-1006.

66 Dinoso VP, Murthy SNS, Goldstein J, Rosner B. Basal motor activity of the distal colon: a reappraisal. Gastroenterologv $1983 ; 85: 637-42$

67 Stevens CE. Comparative physiology of the vertebrate digestive system. Cambridge University Press, 1988.

68 Christensen J. Gross and microscopic anatomy of the large intestine. In: Phillips SF, Pemberton JH, Shorter RG, eds. The large intestine: physiologv, pathophwsiologv, and disease. New York: Raven Press, 1991: 13-35.

69 Christensen J, Caprilli R, Lund GF. Electrical slow waves in circular muscle of the cat colon. Am $\mathcal{F}$ Phisiol 1969; 217 : $771-6$.

70 El-Sharkawy TY. Electrical activities of the muscle lavers of the canine colon. 7 Physiol 1983; 342:67-83.

71 Huizinga JD, Daniel EE. Motor functions of the colon. In: Phillips SF, Pemberton JH, Shorter RG, eds. The large intestine: physiologv, pathophwsiologv, and disease. New York: Raven Press, 1991: 93-114.

72 Schuurkes JAJ, Tukker JJ. The interdigestive colonic motor complex of the dog. Arch Int Pharmacods' Ther 1980; 247: $329-34$

73 Sarna SK, Condon R, Cowles V. Colonic migrating and nonmigrating motor complexes in dogs. Am 7 Phwsiol 198t: 246: G355-60.

$7+$ Crowell MD, Musial F, French W. Kittur D, Anderson D. Whitehead WE. Prolonged ambulatory monitoring of colonic motor activity in the pig. Phy'siol Behav (in press

75 Furukawa Y, Cook IJ, Panagopoulos V. McEvoy D, Sharp D, Simula M. Relationship between sleep patterns and human colonic motor patterns. Gastroenterologv 1991: 100: Attt.

76 Gill RC, Kellow JE, Browning C, Wingate DL. The use of 
intraluminal strain gauges for recording ambulant small bowel motility. Am f Phvsiol 1990; 258: G610-5.

77 Steadman CJ, Phillips SF, Camilleri M, Haddad AC, Hanson $\mathrm{RB}$. Variation of muscle tone in the human colon. Gastroenterology 1991; 101: 373-81.

78 Vassallo MJ, Camilleri M, Phillips SF, Talley NJ, Hanson RB, Haddad AC. Colonic tone and motility in diarrheapredominant irritable bowel syndrome (IBS). Gastroenterology 1991; 100: A505.

79 Bassotti G, Betti C, Pelli MA, Morelli A. Extensive investigation of colonic motility with pharmacological testing is usefu for selecting surgical options in patients with inertia colica. Am f Gastroenterol 1992; 87: 143-7.

80 Leon SH, Krishnamurti S, Schuffler MD. Subtotal colectomy for severe idiopathic constipation. A follow-up study of 13 patients. Dig Dis Sci 1987; 32: 1249-54.
81 Vasilevsky CA, Nemer FD, Balcos EG, Christenson CE, Goldberg SM. Is subtotal colectomy a viable option in the management of chronic constipation? Dis Colon Rectum management of

82 Kamm MA, Hawley PR, Lennard-Jones JE. Outcome of colectomy for severe idiopathic constipation. Gut 1988; 29 . 969-73.

83 Yoshioka K, Keighley MRB. Clinical results of colectomy for severe constipation. BrF Surg 1989; 76: 600-4.

84 Pinho M, Yoshioka K, Keighley MRB. Long term results of anorectal myectomy for chronic constipation. Br $\mathcal{F}$ Surg 1989; 76: 1163-4.

85 Kumar D, Waldron D, Williams NS, Wingate DL. Slowtransit constipation: a pan-enteric motor disorder? Gastroenterologv 1989; 96: A277. 